\title{
Using Language and Affective Profiles to Investigate Differences between Individuals
}

\author{
Danilo Garcia ${ }^{1-5^{*}}$, Oscar NE Kjell ${ }^{2,5}$, Sverker Sikström ${ }^{2,5}$ and Trevor Archer ${ }^{2,3}$ \\ ${ }^{1}$ Department of Psychology, University of Gothenburg, Gothenburg, Sweden \\ ${ }^{2}$ Network for Empowerment and Well-Being, Sweden \\ ${ }^{3}$ Blekinge Centre of Competence, Blekinge County Council, Karlskrona, Sweden \\ ${ }^{4}$ Institute of Neuroscience and Physiology, University of Gothenburg, Gothenburg, Sweden \\ ${ }^{5}$ Department of Psychology, Lund University, Lund, Sweden
}

\begin{abstract}
The affective profiles model (i.e., four possible profiles based on the combination of people's high/low positive/ negative affect) has led to a great number of studies on individual differences during the past ten years. Nevertheless only a handful of these studies have investigated actual behavior. Here we put forward two ways for analyzing online behavior (i.e., Facebook status updates) using data published elsewhere. We used the affective profiles model as the framework to investigate individual differences in the words people use when they write on Facebook and the semantic content of their status updates. We suggest that the use of computerized methods to quantify and analyze text need to be used in order to move the affective profiles model into the era of big text data.
\end{abstract}

\section{Introduction}

Presenting affect as being composed of two systems, each one of them categorized as high and low, leads to four different combinations beyond a two-system approach [1]. In this line of thinking, Archer et al. have theorized on four possible affective profiles based on the combination of people's affectivity levels: self-fulfilling (high positive affect, low negative affect); high affective (high positive affect, high negative affect); low affective (low positive affect, low negative affect); and self-destructive (low positive affect, high negative affect). For the past ten years, the affective profiles model has led to a great number of studies (Figure 1) that have investigated individual differences in illbeing and well-being [2]. Nevertheless, most of these studies have used self-reports, that is, only a handful of studies have investigated actual behavior among individuals with different profiles. In this context, individuals' activities on the Internet (e.g., connecting to others, expressing preferences, status updates) provide excellent observable data for studying human behavior [3,4]. However, the amount of text data is hard to handle using common qualitative methods.

In recent years, the advancement of computerized techniques has facilitated handling big text corpus. Here we put forward two ways of analyzing big text corpus using data published elsewhere. Importantly, the affective profiles model can be used as the framework for this type of analysis, that is, as a model to organize text data.

\section{Method}

Participants $(\mathrm{N}=304)$ were recruited through Amazon's Mechanical Turk (https://www.mturk.com/mturk/welcome) and asked to provide the 15 latest status updates from their own Facebook account. Affectivity was measured using the Emotional Well-Being Scales [5]. All analyses were carried out using Semantic Excel, which is a webbased software developed by S. Sikström. This software is specifically developed to create and analyze quantified representations of text (www.semanticexcel.com).

\section{Results and Discussion}

As the first part of the analyses, we simply compared the frequency of the words in the participants' status updates, for each affective profile, to the word frequency in the Google n-grams database (Figure 2a). This database (http://ngrams.googlelabs.com) comprises probably the largest amount of Terabytes of text data available to the public in different languages (for recent description of the Google n-gram database see Lin et al. [6]). We also compared the words in status updates of participants with one profile to those in the rest of the status updates in the dataset at hand (Figure $2 b$ ). Figure $2 \mathrm{a}$ and $2 \mathrm{~b}$ show the results of these analyses, in which the font sizes of the words in the word clouds are proportional to the square root of the chi-square value associated with these frequencies. The 100 words with the largest chi-squared values are plotted. These results suggest that the participants with different affective profiles generated different status updates, as illustrated by the different words in each word cloud (Figure 2a and 2b). These differences were not only in relation to all words found in natural language (i.e., Google n-grams) but also between participants with a specific profile and the rest of the participants.

The second method used here for quantitatively analyze texts was the Latent Semantic Analysis (LSA) algorithm [7]. This method involves applying an algorithm to create semantic representations of the various semantic based contents. In short, the LSA-algorithm assumes that words that occur close to each other in text can be used as a source of information; which is used to create multi-dimensional semantic representations. That is, the context that words occur in normally consists of a meaning that more often than not corresponds to the meaning of the word [7-9]. As a result, the content can be represented as a vector in a multi-dimensional semantic space. In turn, the semantic representations of single words can be used to summarize larger text by adding the representations, and normalizing the length of the vectors to

*Corresponding author: Garcia D, Network for Empowerment and Well-Being Axel W. Anderssons Väg 8A, SE 371 62, Lyckeby, Sweden; Tel: +46 31 7864694; E-mail: danilo.garcia@icloud.com

Received: April 22, 2016; Accepted: April 27, 2016; Published: May 04, 2016

Citation: Garcia D, Kjell ON, Sikström S, Archer T (2016) Using Language and Affective Profiles to Investigate Differences between Individuals. Clin Exp Psychol 2 123. doi:10.4172/2471-2701.1000123

Copyright: @ 2016 Garcia D ,et al. This is an open-access article distributed under the terms of the Creative Commons Attribution License, which permits unrestricted use, distribution, and reproduction in any medium, provided the original author and source are credited. 
Citation: Garcia D, Kjell ON, Sikström S, Archer T (2016) Using Language and Affective Profiles to Investigate Differences between Individuals. Clin Exp Psychol 2: 123. doi:10.4172/2471-2701.1000123

\begin{tabular}{|c|c|}
\hline \multicolumn{2}{|c|}{ High PA } \\
\hline $\begin{array}{l}\text { Self-Fulfilling } \\
\text { - High levels of psychological well-being: } \\
\text { positive relations to others, autonomy, } \\
\text { environmental mastery, self-acceptance, } \\
\text { personal growth, and purpose in life. } \\
\text { - High levels of subjective well-being: life } \\
\text { satisfaction, high positive affect, low negative } \\
\text { affect, and harmony. } \\
\text { - Low levels of ill-being: low depressive and } \\
\text { stress symptoms and sleeping and } \\
\text { psychophysiological problems. } \\
\text { - Personality: low in Neuroticism, high in } \\
\text { Extraversion, low in Harm Avoidance, high in } \\
\text { Persistence, high in Self-directedness, high in } \\
\text { Cooperativeness, low in Dark Triad traits (i.e., } \\
\text { Machiavellianism, Psychopathy, and } \\
\text { Narcissism). } \\
\text { - Other important characteristics: frequently } \\
\text { physical active, high on spiritual behavior, high } \\
\text { in energy and locomotion ('just do it' } \\
\text { mentality), low in assessment (rumination), } \\
\text { spiritual behavior. }\end{array}$ & $\begin{array}{l}\text { High Affective } \\
\text { - High levels of psychological well-being: } \\
\text { environmental mastery, self-acceptance, } \\
\text { personal growth, and purpose in life. } \\
\text { - Low levels of psychological well-being: } \\
\text { autonomy. } \\
\text { - High levels of subjective well-being: life } \\
\text { satisfaction, high positive affect, and harmony. } \\
\text { - Low levels of subjective well-being: high } \\
\text { negative affect. } \\
\text { - Low levels of ill-being: low depressive } \\
\text { symptoms. } \\
\text { - High levels of ill-being: frequent sleeping and } \\
\text { psychophysiological problems and high stress. } \\
\text {-Personality: high in Neuroticism, high in } \\
\text { Extraversion, high in Harm Avoidance, high in } \\
\text { Reward Dependence, high in Self-directedness, } \\
\text { low in Self-transcendence, high in Dark Triad } \\
\text { traits. } \\
\text { - Other important characteristics: frequently } \\
\text { physical active, high in energy and locomotion } \\
\text { ('just do it' mentality), high in assessment } \\
\text { (rumination). }\end{array}$ \\
\hline Low NA & High NA \\
\hline $\begin{array}{l}\text { Low Affective } \\
\text { - High levels of psychological well-being. } \\
\text { - High levels of subjective well-being: life } \\
\text { satisfaction, low negative affect, and harmony. } \\
\text { - Low levels of subjective well-being: low } \\
\text { positive affect. } \\
\text { - Low levels of ill-being: low depressive and } \\
\text { stress symptoms. } \\
\text { - High levels of ill-being: high } \\
\text { psychophysiological and sleeping problems. } \\
\text { - Personality: low in Extraversion, high in } \\
\text { Emotional Stability, low in Persistence, low in } \\
\text { Self-directedness, low in Cooperativeness, low } \\
\text { in Dark Triad traits. } \\
\text { - Other important characteristics: not physical } \\
\text { active, low in energy and locomotion ('just do } \\
\text { it' mentality), high in assessment (rumination). }\end{array}$ & $\begin{array}{l}\text { Self-Destructive } \\
\text { - Low levels of psychological well-being. } \\
\text { - Low levels of subjective well-being. } \\
\text { - High levels of ill-being: high in depressive and } \\
\text { stress symptoms and psychophysiological and } \\
\text { sleeping problems. } \\
\text { - Personality: high in Introversion, high in } \\
\text { Neuroticism, low in Persistence, high in Harm } \\
\text { Avoidance, low in Self-directedness, low in } \\
\text { Cooperativeness, high in Dark Triad traits. } \\
\text { - Other important characteristics: not physical } \\
\text { active, low energy and locomotion ('just do it' } \\
\text { mentality), high in assessment (rumination), } \\
\text { low in spiritual behavior. }\end{array}$ \\
\hline
\end{tabular}

Figure 1: Summary of the results using the affective profiles model during the past decade. Most of these results are based on survey studies with a few exceptions using behavioral data.

one. The similarity between semantic representations can be measured by the cosines of the angle between the vectors, which is mathematically equivalent to multiplying each dimension with each other and adding the resulting products. This similarity measure can then be used in standard statistical procedures such as correlations, regressions, t-tests, analysis of variance, etcetera [10-14]. Here we conducted a semantic difference test to examine whether sets of Facebook status updates significantly differed between participants with distinct affective profiles (Table 1). In these tests, after a semantic representation of the status updates for each profile is created, a difference is calculated by subtracting one profile's semantic representation from the one that is under comparison using a $10 \%$-leave-out method. This difference is used to measure the semantic distance of each text (when that text is left out in the $10 \%$-leave-out procedure) in each profile to be compared.
A standard t-test was finally used to investigate the difference between semantic distances. As seen in Table 1, the content in Facebook status updates written by individuals with a low affective profile differed to the content in Facebook status updates written by individuals with any of the other profiles [15-17].

\section{Conclusion and Final Remarks}

All in all, the model put forward by Archer et al. has served as a good framework for understanding the way people's affective system regulates behavior. We suggest that the use of computerized methods to quantify and analyze text need to be used in order to move the affective profiles model into the era of big text data.

A third method for analyzing text, is the use of words with predefined sets of psycholinguistic characteristics (i.e., word-norms) 
Citation: Garcia D, Kjell ON, Sikström S, Archer T (2016) Using Language and Affective Profiles to Investigate Differences between Individuals. Clin Exp Psychol 2: 123. doi:10.4172/2471-2701.1000123

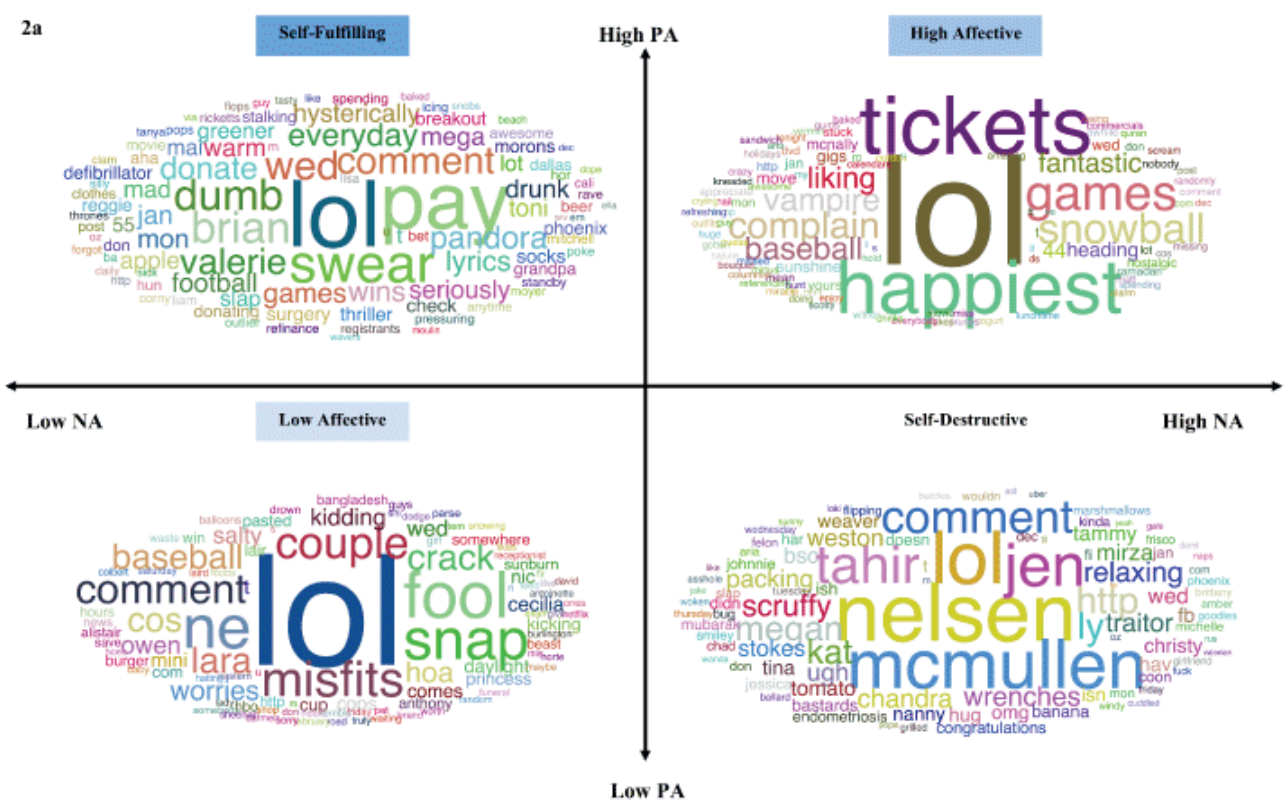

Figure 2a: Users' status updates compared to general word frequency in Google n-grams organized on the basis of Facebook users' type of affective profile (i.e., selfdestructive, low affective, high affective, and self-fulfilling).

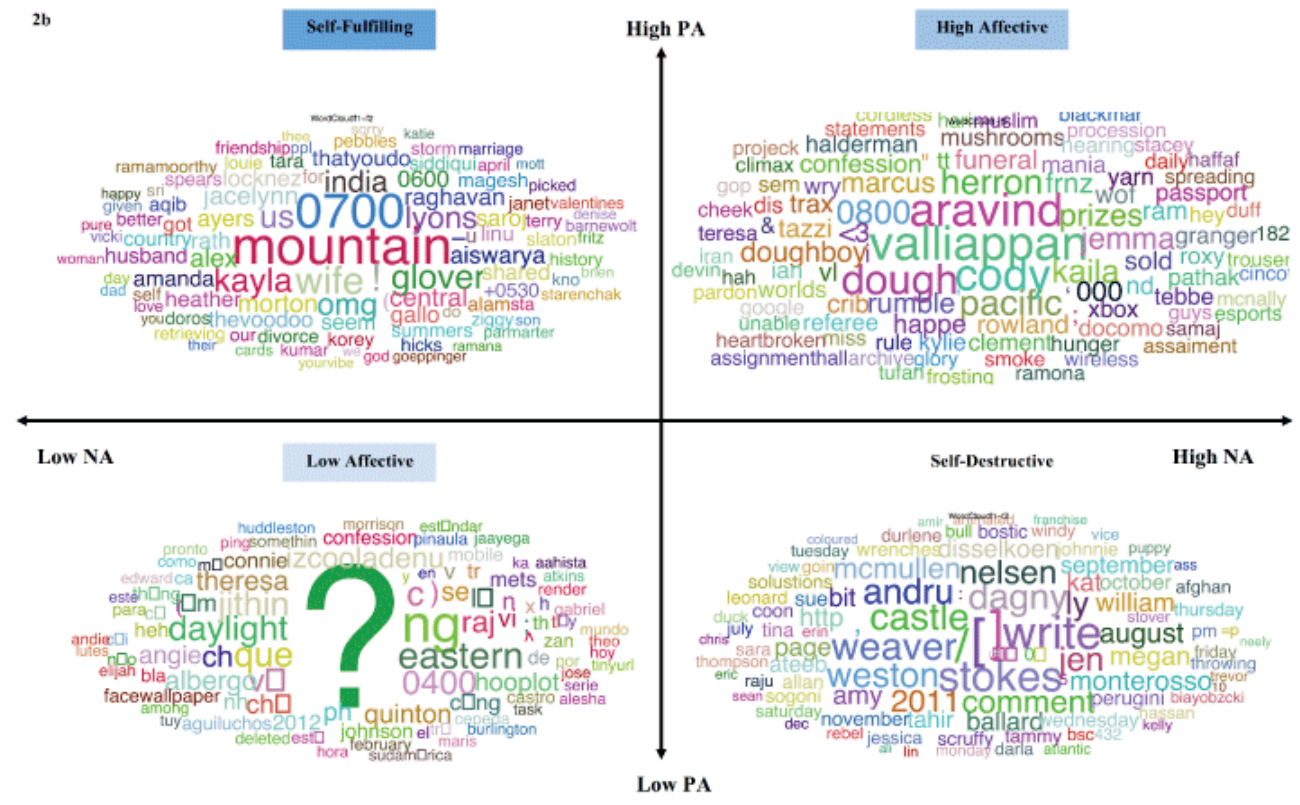

Figure 2b: Word clouds of Facebook status updates. Word clouds showing words that differed in occurrence between Facebook users' status updates with each specific affective profile and the rest of the Facebook users' status updates in the same data set.

to further examine differences between sets of narratives (e.g., status updates) [16]. These word-norms are created by asking an independent sample of participants to generate words they associate to hypothesisrelevant key words, such as, "happiness" if the researcher is interested in knowing if people with distinct profiles differ between each other in how happy participants are on the basis of their status updates.
One way or the other, the use of language-based measures of behavior in conjunction with person-centered models, such as the affective profiles model, might help to the understanding of how human beings behave and why do they behave in certain, specific and sometimes unpredictable ways. 
Citation: Garcia D, Kjell ON, Sikström S, Archer T (2016) Using Language and Affective Profiles to Investigate Differences between Individuals. Clin Exp Psychol 2: 123. doi:10.4172/2471-2701.1000123

\begin{tabular}{|c|c|c|c|}
\hline & Self-destructive $(\mathbf{n}=\mathbf{1 1 3})$ & Low Affective $\mathbf{( n = 4 0 )}$ & High Affective $(\mathbf{n}=\mathbf{3 3})$ \\
\hline Self-destructive & - & - & \\
\hline Low Affective & $0.38^{* *}$ & $0.46^{* *}$ & - \\
\hline High Affective & $-0.06 \mathrm{~ns}$ & $0.49^{* *}$ & $-0.10 \mathrm{~ns}$ \\
\hline Self-fulfilling & $-0.20 \mathrm{~ns}$ & - & \\
\hline
\end{tabular}

Table 1: Effect sizes showing semantic differences in status updates between individuals with distinct affective profiles. Note: ${ }^{* *} p<.01 ;{ }^{* \star *} p<.001$; ns: not significant

"Language is surely too small a vessel to contain these emotions of mind and body that have somehow awakened a response in the spirit." By Marguerite Radclyffe Hall

\section{Acknowledgements}

The development of this article was supported by a grant from The Swedish Research Council (Dnr. 2015-01229). The funders had no role in study design, data collection and analysis, decision to publish, or preparation of the manuscript.

\section{Conflict of Interest}

Dr. Danilo Garcia is the Director of the Blekinge Center of Competence, which is the Blekinge County Council's research and development unit. The Center works on innovations in public health and practice through interdisciplinary scientific research, person-centered methods, community projects, and the dissemination of knowledge in order to increase the quality of life of the habitants of the county of Blekinge, Sweden. $\mathrm{He}$ is also an Associate Professor at the University of Gothenburg and together with Professor Trevor Archer and Associate Professor Max Rapp Ricciardi, the leading researcher of the Network for Empowerment and Well-Being. Erik Lindskär is a research assistant at the Blekinge Center of Competence and a member of the Network for Empowerment and Well-Being. The data used here was used in an earlier study published elsewhere, see [12].

\section{References}

1. Garcia D (2011) Adolescents' happiness: The role of the affective temperament model on memory and apprehension of events, subjective well-being, and psychological well-being. Ph.D. Thesis, University of Gothenburg, Gothenburg.

2. Cloninger CR, Garcia D (2015) The heritability and development of positive affect and emotionality. Genetics of psychological well-being-the role of heritability and genetics in positive psychology pp. 97-113.

3. Dodds PS, Danforth CM (2010) Measuring the happiness of large-scale written expression: Songs, blogs, and presidents. Journal of Happiness Studies 11: 441-456.

4. Dodds PS, Harris KD, Kloumann IM, Bliss CA Danforth CM (2011) Temporal Patterns of Happiness and Information in a Global Social Network: Hedonometrics and Twitter. PLoS ONE 6: e26752.

5. Diener E, Biswas-Diener R (2008) Happiness - Unlocking the mysteries of psychological wealth. Oxford: Blackwell Publishing.

6. Lin Y, Michel JB, Lieberman Aiden E, Orwant J, Brockman W, et al. (2012) Syntactic annotations for the Google books Ngram corpus. In Proceedings of the 50th Annual Meeting of the Association for Computational Linguistics, 8-14 July, Jeju, Republic of Korea (pp. 169-174).

7. Landauer TK, Dumais S (1997) A solution to Plato's problem: The Latent Semantic Analysis theory of acquisition, induction, and representation of knowledge. Psychological Review 104: 211-240.

8. Landauer TK (2008) LSA as a theory of meaning. In Landauer TK, McNamara DS, Dennis S, Kintsch W Handbook of Latent Semantic Analysis. Mahwah: Lawrence Erlbaum Associates.

9. Landauer TK, McNamara DS, Dennis S, Kintsch W (2008) Handbook of Latent Semantic Analysis. Mahwah: Lawrence Erlbaum Associates.

10. Garcia D, Sikström S (2013a) A Collective Theory of Happiness: Words Related to the Word Happiness in Swedish Online Newspapers. Cyberpsychol Behav Soc Netw 16: 469-472.

11. Garcia D, Sikström S (2013b) Quantifying the Semantic Representations in Adolescents' Memories of Positive and Negative Life Events. Journal of Happiness Studies 14: 1309-1323.

12. Garcia D, Sikström S (2014) The dark side of Facebook: Semantic representations of status updates predict the Dark Triad of personality. Personality and Individual Differences 67: 92-96.

13. Rosenberg P, Sikström S, Garcia D (2013) The difference between living biblically and just imagining it: A study on experiential-based learning among Swedish adolescents. School Psychology International 34: 565-571.

14. Rosenberg P, Sikström S, Garcia D (2016) The A(ffective) B(ehavioral) $\mathrm{C}$ (ognitive) of Taboo Words in Natural Language: The Relationship Between Taboo Words' Intensity and Frequency. Under editorial evaluation.

15. Garcia D, Anckarsäter H, Kjell ONE, Archer T, Rosenberg P, et al. (2015)Agentic, Communal, and Spiritual Traits are Related to the Semantic Representation of Written Narratives of Positive and Negative Life Events. Psychology of WellBeing: Theory, Research and Practice 5: 1-20.

16. Garcia D, Kjell ONE, Sikström S (In press). A Collective Picture of What Makes People Happy: Words Representing Social Relationships, not Money or Materia Things, are Recurrent with the Word 'Happiness' in Online Newspapers. In Riva G, Wiederhold BK, Cipresso P (Eds.), The Psychology of Social Networking. Personal Experience in Online Community. DeGruyter Open.

17. Garcia D, MacDonald S, Archer T (2015) Two different approaches to the affective profiles model: median splits (variable-oriented) and cluster analysis (person-oriented). PeerJ 3: e1380. 